\title{
RECENT \\ DEVELOPMENTS \\ IN THEORETICAL \\ STUDIES OF \\ PROTEINS
}


This page is intentionally left blank 


\section{Advanced Series in Physical Chemistry - Vol. 7}

RECENT

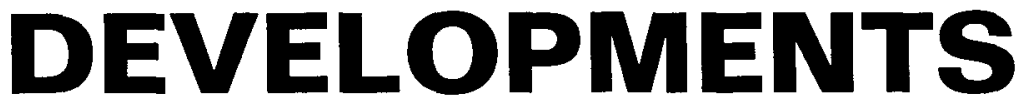

IN

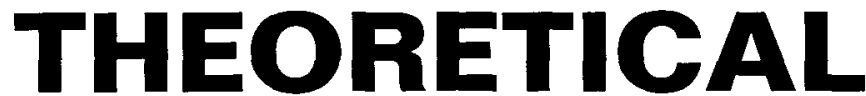

STUDIES OF

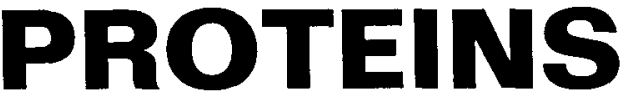

Editor

Ron Elber

Department of Physical Chemistry

Hebrew University

Israel 


\section{Published by}

World Scientific Publishing Co. Pte. Ltd.

P O Box 128, Farrer Road, Singapore 912805

USA office: Suite 1B, 1060 Main Street, River Edge, NJ 07661

UK office: 57 Shelton Street, Covent Garden, London WC2H 9HE

\section{British Library Cataloguing-in-Publication Data}

A catalogue record for this book is available from the British Library.

\section{RECENT DEVELOPMENTS IN THEORETICAL STUDIES OF PROTEINS}

Copyright (C) 1996 by World Scientific Publishing Co. Pte. Ltd.

All rights reserved. This book, or parts thereof, may not be reproduced in any form or by any means, electronic or mechanical, including photocopying, recording or any information storage and retrieval system now known or to be invented, without written permission from the Publisher.

For photocopying of material in this volume, please pay a copying fee through the Copyright Clearance Center, Inc., 222 Rosewood Drive, Danvers, MA 01923, USA. In this case permission to photocopy is not required from the publisher.

ISBN 981-02-2196-7

Printed in Singapore. 


\section{ADVANCED SERIES IN PHYSICAL CHEMISTRY}

\section{INTRODUCTION}

Many of us who are involved in teaching a special-topic graduate course may have the experience that it is difficult to find suitable references, especially reference materials put together in a suitable text format. Presently, several excellent book series exist and they have served the scientific community well in reviewing new developments in physical chemistry and chemical physics. However, these existing series publish mostly monographs consisting of review chapters of unrelated subjects. The modern development of theoretical and experimental research has become highly specialized. Even in a small subfield, experimental or theoretical, few reviewers are capable of giving an in-depth review with good balance in various new developments. A thorough and more useful review should consist of chapters written by specialists covering all aspects of the field. This book series is established with these needs in mind. That is, the goal of this series is to publish selected graduate texts and stand-alone review monographs with specific themes, focusing on modern topics and new developments in experimental and theoretical physical chemistry. In review chapters, the authors are encouraged to provide a section on future developments and needs. We hope that the texts and review monographs of this series will be more useful to new researchers about to enter the field. In order to serve a wider graduate student body, the publisher is committed to making available the monographs of the series in a paperbound version as well as the normal hardcover copy.

Cheuk-Yiu Ng 
This page is intentionally left blank 


\section{PREFACE}

Modeling, simulations and theoretical studies of biological molecules have expanded tremendously in the last few years. Some of the growth was attributed to the rapid advances in computer technology. Faster and more economical computers made it possible to simulate larger systems for longer periods of time at lower costs. The impact on simulations of biological macromolecules such as proteins was thus profound.

However, this was only part of the story. Equally significant has been the explosion in the number of computational tools available today to investigators in the field. This is especially striking considering that the field was overwhelmed, just a few years ago, by essentially one methodology - the Molecular Dynamics (MD) approach. The strength of MD is its simplicity and generality. The prime weakness of the MD approach is the restriction on the time scale and the limited conformation space that one can sample.

A few recent uses of the MD approach are described by $\mathrm{K}$. Kuczera. The studies of dynamics and thermodynamics of the globins are of special interest. This is due to the wealth of experimental data available, which makes detailed atomic studies worthwhile. Furthermore, since many processes in the globins occur rapidly (e.g. nitric oxide diffusion and recombination), the limited time scale of Molecular Dynamic simulations is less of a problem.

Due to the specificity of proteins and their complexity, it was difficult to come up with an analytical theory of proteins. It is desirable of course to have methods of sufficient generality to address more than one or a few special cases.

Difficulty is not impossibility. Motivated by a problem (protein folding) of utmost importance in biochemistry and biophysics, researchers from different fields entered the area of theoretical biophysics. Armed with a set of tools new to biophysics of proteins, researchers understood a number of beautiful and general principles of protein design. The "polymer physicists"' approach to proteins is discussed by Garel, Orland, and Thirumalai. 
The title of the chapter "Analytical theories of protein folding" clearly indicates that this is one contribution that is independent of the revolution in computational power.

Another development motivated by the protein folding problem is the work by Luthey-Schulten, Goldstein and Wolynes. This investigation aims at the design of an effective potential that will fold a protein to its correct structure at maximum speed. The principle of the design of such a potential came from the "physicists" approach to proteins and spin glass models. In fact, Peter Wolynes should be credited for many early studies and ideas on the relation between spin glasses and proteins.

Even if an exact potential energy surface is provided, the problem is not yet solved. It is still a non-trivial problem; how to find the global (free) energy minimum among all of the possible alternative conformations. Fortunately, a number of original algorithms appeared in the field of "global optimization", suggesting that the problem previously believed to be too difficult to solve may be more tractable after all. Straub describes the philosophy and the applications of the new class of optimization techniques.

Low energy minima provide information on probable structures. However, they cannot tell us about kinetics. To bridge the gap between static information and dynamics it is necessary to compute properties related to transitions between alternative minima. Possible approaches to the problem are described in Chapter 2.

Finally we are concerned with electrostatic and ion channels. Ion channels belong to a specific type of proteins that transport ions through membranes. While electric field is important almost everywhere in molecular biology, its importance cannot be overemphasized in channel, in which a charged entity (the ion) is passed through a low dielectric medium (the membrane) using a special biological machinery (the channel). The discussion on electrostatic properties in channels and beyond, in dynamics and in statics of biomolecules, is provided in the last chapter by Eisenberg. 


\section{CONTENTS}

Introduction $\quad$ v

Preface vii

1. Dynamics and Thermodynamics of Globins 1 Krzysztof Kuczera

2. Reaction Path Studies of Biological Molecules 65 Ron Elber

3. Optimization Techniques with Applications to Proteins

John E. Straub

4. Analytical Theories of Protein Folding 197 T. Garel, H. Orland and D. Thirumalai

5. Atomic Biology, Electrostatics, and Ionic Channels 269 R. S. Eisenberg

6. The Statistical Mechanical Basis of Sequence Alignment Algorithms for Protein Structure Recognition

Richard A. Goldstein, Zaida A. Luthey-Schulten and Peter G. Wolynes

Index 